\title{
IMPACT OF SOCIAL ISOLATION DUE TO COVID-19 ON HEALTH IN OLDER PEOPLE: MENTAL AND PHYSICAL EFFECTS AND RECOMMENDATIONS
}

\author{
W. SEPÚLVEDA-LOYOLA ${ }^{1}$, I. RODRÍGUEZ-SÁNCHEZ², P. PÉREZ-RODRÍGUEZ ${ }^{3}$, F. GANZ ${ }^{4}$, \\ R. TORRALBA ${ }^{5}$, D.V. OLIVEIRA ${ }^{6}$, L. RODRÍGUEZ-MAÑAS ${ }^{7}$
}

\begin{abstract}
1. Program of Masters and Doctoral degree in Rehabilitation Sciences, Londrina State University (UEL) and University North of Paraná (UNOPAR), Londrina, Brazil; 2. Department of Geriatric Medicine. Complejo Hospitalario de Navarra, Spain; 3. Department of Geriatric Medicine. Hospital Universitario La Paz, Madrid, Spain; 4. Faculty of Rehabilitation

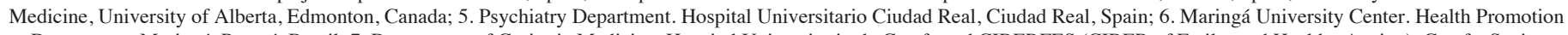
Department. Maringá, Paraná, Brazil; 7. Department of Geriatric Medicine. Hospital Universitario de Getafe and CIBERFES (CIBER of Frailty and Healthy Ageing), Getafe, Spain. Corresponding author: Leocadio Rodríguez-Mañas, MD. Department of Geriatric Medicine. Hospital Universitario de Getafe. Carretera Madrid -Toledo Km 12.500, 28905 Getafe, Madrid, Spain Telephone: (+34) 91-683-93-60. E-Mail: leocadio.rodriguez@salud.madrid.org
\end{abstract}

\begin{abstract}
Objectives: To review the impact of social isolation during COVID-19 pandemic on mental and physical health of older people and the recommendations for patients, caregivers and health professionals. Design: Narrative review. Setting: Non-institutionalized community-living people. Participants: 20.069 individuals from ten descriptive cross-sectional papers. Measurements: Articles since 2019 to 2020 published on Pubmed, Scielo and Google Scholar databases with the following MeSh terms ('COVID-19', 'coronavirus', 'aging', 'older people', 'elderly', 'social isolation' and 'quarantine') in English, Spanish or Portuguese were included. The studies not including people over 60 were excluded. Guidelines, recommendations, and update documents from different international organizations related to mental and physical activity were also analysed. Results: 41 documents have been included in this narrative review, involving a total of 20.069 individuals (58\% women), from Asia, Europe and America. 31 articles included recommendations and 10 addressed the impact of social distancing on mental or physical health. The main outcomes reported were anxiety, depression, poor sleep quality and physical inactivity during the isolation period. Cognitive strategies and increasing physical activity levels using apps, online videos, telehealth, are the main international recommendations. Conclusion: Mental and physical health in older people are negatively affected during the social distancing for COVID-19. Therefore, a multicomponent program with exercise and psychological strategies are highly recommended for this population during the confinement. Future investigations are necessary in this field.
\end{abstract}

Key words: Social isolation, COVID-19, physical function, mental health, aging.

\section{Introduction}

The COVID-19 pandemic due to SARS-Cov-2 has rapidly spread all over the world since last December. Although its prevalence in the community is uncertain due to the asymptomatic cases, all age groups seems to be similarly affected (1). However, older people are at higher risk of suffering negative outcomes, which can lead to an elevated rate of mortality, being five times higher than the global average for those older than 80 years old (2). Over $95 \%$ of fatalities due to COVID-19 in Europe and around 80\% in China have included people older than 60 years-old $(3,4)$. In the US, $80 \%$ of deaths were among adults 65 and over (5). Hence, health strategies to avoid spread of coronavirus (such as quarantine and social distancing) are important $(6,7)$.

The World Health Organization (WHO) describes a close relationship between physical and mental functions with the level of self-governance and social participation in the community[8]. Social participation has been defined as active participation in a religious, sports, cultural, recreational, political, and volunteer community organizations (9-12). Various studies have reported protective effects of social participation for the health of the elderly, being considered as a stimulus to increase the level of physical activity and cognitive functions $(9,13,14)$. The social participation has

been associated with a better quality of life, more muscle mass, balance, cognition and lower comorbidities and disability in older people $(9,13,15-20)$. Participating in social meetings and activities are stimuli that increase the level of physical activity as well as the interaction with other older adults stimulating sensory systems, self-esteem, affectivity, emotional and psychological support $(9,13,21)$. As a preventive measure during the COVID-19 pandemic, community organizations have closed. Old people are constrained from visits with family members, therefore the social participation have been restricted (7). Thus, the decreasing of social interaction produced by social distancing could have a negative impact on mental and physical health in older people (22-24), since it has limited the social participation in community organizations and in family activities $(23,25)$.

WHO defines the 'intrinsic capacity' as the 'composite of all the physical, functional, and mental capacities of an individual' (26-28), changing the focus from a negative aging (disability) towards a positive one (optimal aging), being related to the onset of autonomy decline, falls and death (27). Physical activity has a positive impact on the health and quality of life, reducing the risk of functional and cognitive impairment, falls and risk of fractures, depression, disability, risk of geriatrics syndromes, hospitalization rates and, consecutively, mortality in older people (29). 


\section{THE JOURNAL OF NUTRITION, HEALTH \& AGING}

Not only the physical activity is affected during quarantine, but also mental health. Several studies have described mental health consequences in previous quarantines, such as higher risk of depression (30), emotional disturbance (31), stress (32), low mood (33), irritability (33), or insomnia (33), being also associated with higher rates of suicide in elderly population (34). However, the effects of COVID-19 quarantine on the health of older adults have not yet been broadly studied. Hence, the aim of this review is to analyse the potential effects of social isolation caused by COVID-19 pandemic on mental and physical health in older adults. Additionally, we have analysed the recommendations and proposed activities to avoid mental and functional decline to carry out at home.

\section{Methods}

In this narrative review, the literature search was performed by three authors (WSL, IRS and RT). Pubmed, Scielo and Google Scholar databases were consulted using the following terms ('COVID-19', 'coronavirus', 'aging', 'older people', 'elderly', 'social isolation' and 'quarantine'). Articles of any type of methodological design published from 2019 to 2020 (May 20th), in English, Spanish or Portuguese were included. Articles that did not include subjects $>60$ years old were excluded. Additionally, we have searched papers, guidelines, recommendations and update documents from different international organizations related to mental and physical activity. The lists of articles in the databases were downloaded in "bib format" and stored in Mendeley for analysis of duplicate articles, title, and abstract reading. The content of the review was divided into two main areas: 1) effect of the reduction of social participation produced by quarantine for COVID-19 on mental and physical health in elderly people, and 2) recommendations for mental and physical health of older people during the COVID-19 quarantine.

\section{Results}

\section{Search results}

A detailed summary of the literature search is provided in Figure 1. Six hundred and ninety unique records were identified through database and handsearching, resulting in ten articles involving 20.069 participants included in the final review (women 58\%) from Asia, Europe, and America. Of these, 9 adopted a cross-sectional design, and 1 was a qualitative design. All of them are descriptive studies. Additionally, 31 articles from experts and authors about recommendations were considered in the full-text review. A summary of the characteristics of the included studies is presented in table 1 .
Figure 1

Selection process of studies

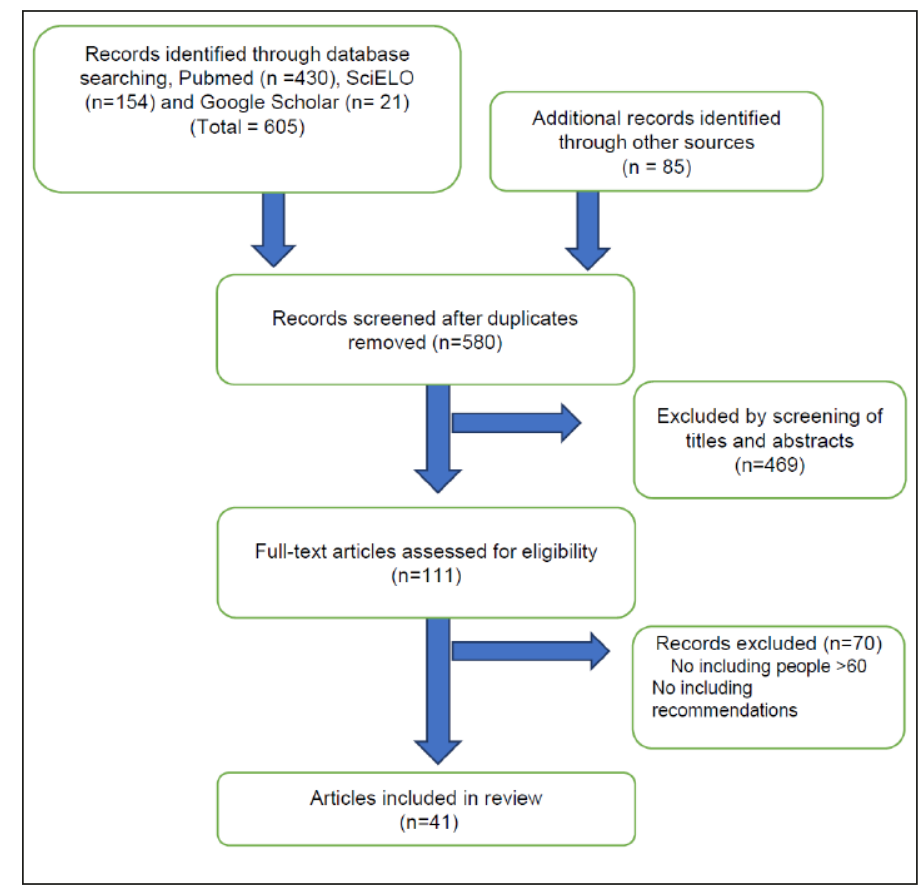

Effect of the reduction of social participation produced by quarantine for COVID-19 on mental and physical health in elderly people

\section{Mental Health}

Our results are based on summary data from eight crosssectional studies (35-42). The prevalence of anxiety ranged from $8.3 \%, 18.7 \%$ and $35.1 \%$ to $49.7 \%(36,38)$; corresponding values from depression were $14.6 \%, 20.1 \%, 32.8 \%, 37.8 \%$ and $47.2 \%$ (36-38). Finally, sleep disturbances were observed in $18.2 \%$ (38) and $36.4 \%$ (37) among the participants. Six of them $(36,38-42)$ pointed out an increased level of psychological stress defined as higher anxiety $(36,38-41)$, depression (36, 38-41) and loneliness (42) levels and poorer sleep quality (38) during the lock-down by coronavirus. Nevertheless, in one study (35) isolation period by COVID-19 turned out in a mild stressful impact. Additionally, only one study (37) showed that people during quarantine had lower anxiety levels, but more sleep disturbances.

Risk factors associated to these results varied across the studies. Being female $(36,39,42)$, having a negative selfperception of aging (42), healthcare workers (38), family and personal resources (42), time devoted to COVID-19 information (42), having an acquaintance or a family member infected with COVID-19 or a previous history of medical problems (39) seem to act as potential risk factors. 
IMPACT OF SOCIAL ISOLATION DUE TO COVID-19 ON HEALTH IN OLDER PEOPLE

\section{Table 1}

Characteristics of the included studies related to mental and physical health effects by COVID-19 quarantine

\begin{tabular}{|c|c|c|c|c|c|c|}
\hline First author & Country & Study design & Sample size & Age & Gender (female) & Main result \\
\hline \multicolumn{7}{|l|}{ Mental health } \\
\hline Zhang Y et al 2020 (35). & China & Cross-sectional & 263 & $\geq 18(20.5 \%>50)$ & $157(59.7 \%)$ & $\begin{array}{l}\text { The overall IES score indicated a mild stressful impact } \\
52.1 \% \text { felt horrified and apprehensive due to the pandemic, } \\
\text { but they did not feel helpless. }\end{array}$ \\
\hline Lei L et al 2020 (36). & China & Cross-sectional & 1593 & $\geq 18(6.8 \%>50)$ & $976(61.3 \%)$ & $\begin{array}{l}\text { The prevalence of anxiety and depression of people affected } \\
\text { by quarantine is higher vs not affected. }\end{array}$ \\
\hline Yuan S et al 2020 (37). & China & Cross-sectional & 939 & $\geq 18(1.4 \%>60)$ & $582(62 \%)$ & $\begin{array}{l}\text { Emotional state (anxiety) and behaviour improved, but the } \\
\text { quality of sleep got worse. }\end{array}$ \\
\hline Huang Y et al 2020 (38). & China & Cross-sectional & 7236 & $6-80$ & $3952(54.6 \%)$ & $\begin{array}{l}\text { High prevalence of anxiety and poor sleep quality especially } \\
\text { on young people, healthcare workers and those who spent } \\
\text { too much time thinking about the outbreak }\end{array}$ \\
\hline Mazza C et al, 2020 (39) & Italy & Cross-sectional & 2766 & $18-90$ & $1982(71.7 \%)$ & $\begin{array}{l}\text { - Female gender, negative affect, and detachment were asso- } \\
\text { ciated with higher levels of psychological distress } \\
\text { - Having an acquaintance infected with COVID-19 in- } \\
\text { creased depression and stress } \\
\text { - A history of stressful situations and medical problems } \\
\text { raised depression and anxiety levels } \\
\text { - Having a family member infected with COVID-19 } \\
\text { increased anxiety } \\
\text { - Being young and working outside domicile raised stress } \\
\text { levels }\end{array}$ \\
\hline $\begin{array}{l}\text { Ozamiz-Etxebarria } \mathrm{N} \text { et al } \\
2020[40]\end{array}$ & Spain & Cross-sectional & 976 & $18-78(8 \%>60)$ & $792(81.1 \%)$ & $\begin{array}{l}\text { Higher levels of anxiety, depression and stress were obser- } \\
\text { ved especially in people }<60 \text { and with chronic conditions }\end{array}$ \\
\hline $\begin{array}{l}\text { Losada-Baltar A et al } 2020 \\
\text { (42) }\end{array}$ & Spain & Cross-sectional & 1310 & $18-88(17.3 \%>60)$ & $931(71.1 \%)$ & $\begin{array}{l}\text { Higher loneliness and psychological distress during the } \\
\text { lock-down. } \\
\text { Risk factors associated: female and negative self-perception } \\
\text { of aging }\end{array}$ \\
\hline $\begin{array}{l}\text { Rios-González CM et al } 2020 \\
\text { (41) }\end{array}$ & Paraguay & Cross-sectional & 1180 & $\geq 18(23.8 \% \geq 50)$ & $608(51.5 \%)$ & $\begin{array}{l}\text { Symptoms of anxious or depressive were found mainly at } \\
\text { older people }\end{array}$ \\
\hline \multicolumn{7}{|l|}{ Physical health } \\
\hline Goethals et al. 2020 (43) & France & Qualitative & 6 & $71-91$ & $3(50 \%)$ & $\begin{array}{l}\text { - COVID-19 pandemic has affected the number of seniors } \\
\text { attending group PA programs } \\
\text { - Older adults expressed the need to perform PA at home } \\
\text { - There is a need to help older adults integrate simple and } \\
\text { safe ways to stay physically active in a limited space }\end{array}$ \\
\hline $\begin{array}{l}\text { Castañeda-Babarro et al } 2020 \\
\text { (44) }\end{array}$ & Spain & Cross-sectional & 3800 & $18-64$ & $1746(46 \%)$ & $\begin{array}{l}\text {-PA decreased significantly during confinement in all popu- } \\
\text { lation, especially the vigorous activities and walking time. }\end{array}$ \\
\hline
\end{tabular}

IES: Impact of Event Scale; PA: Physical activity.

\section{Physical Health}

The impact on physical health of the social distancing was studied for two authors $(43,44)$ (Table 1$)$. Goethals et al (43) reported that COVID-19 pandemic has affected the number of seniors attending group physical activity programs. Additionally, Castañeda-Babarro et al (44) observed that the physical activity was highly decreased during confinement in all population, especially the vigorous activities and walking time.

\section{Recommendations for mental health and physical in older people during COVID-19 quarantine}

\section{Mental health}

There are several recommendations related to the patient to deal with this social isolation (Table $2 \mathrm{~A}$ ) such as strengthen social connections $(43,45-48)$ (using internet apps, video chat
$(45,47))$, telephone support lines or support groups $(23,35,49)$, changes on lifestyle (regular sleep-wake up circle (50), physical activity and nutrition habits $(37,51)$ ) and cognitive stimulation (using apps or stimulating mental exercises, especially in those people with previous cognitive impairment (50-52)).

Caregivers have an important and crucial role guaranteeing the physical and mental well-being. To reduce anxiety and feeling of usefulness, letting the person participate in adapted daily activities depending on the cognitive status is recommended (51). The exposure to media must be regulated (53), avoiding doing it in excess and only from official sources $(51,54)$, managing to control the effect of news with traumatic content (51). Explaining clearly (55) or accompanying information with illustrations (53) may help, especially in people with cognitive impairment.

To improve older people resilience, a combination of health education and psychological counselling could be useful. 
THE JOURNAL OF NUTRITION, HEALTH \& AGING

Table 2A

Recommendations of the literature for maintaining mental health in older people during the COVID-19 quarantine

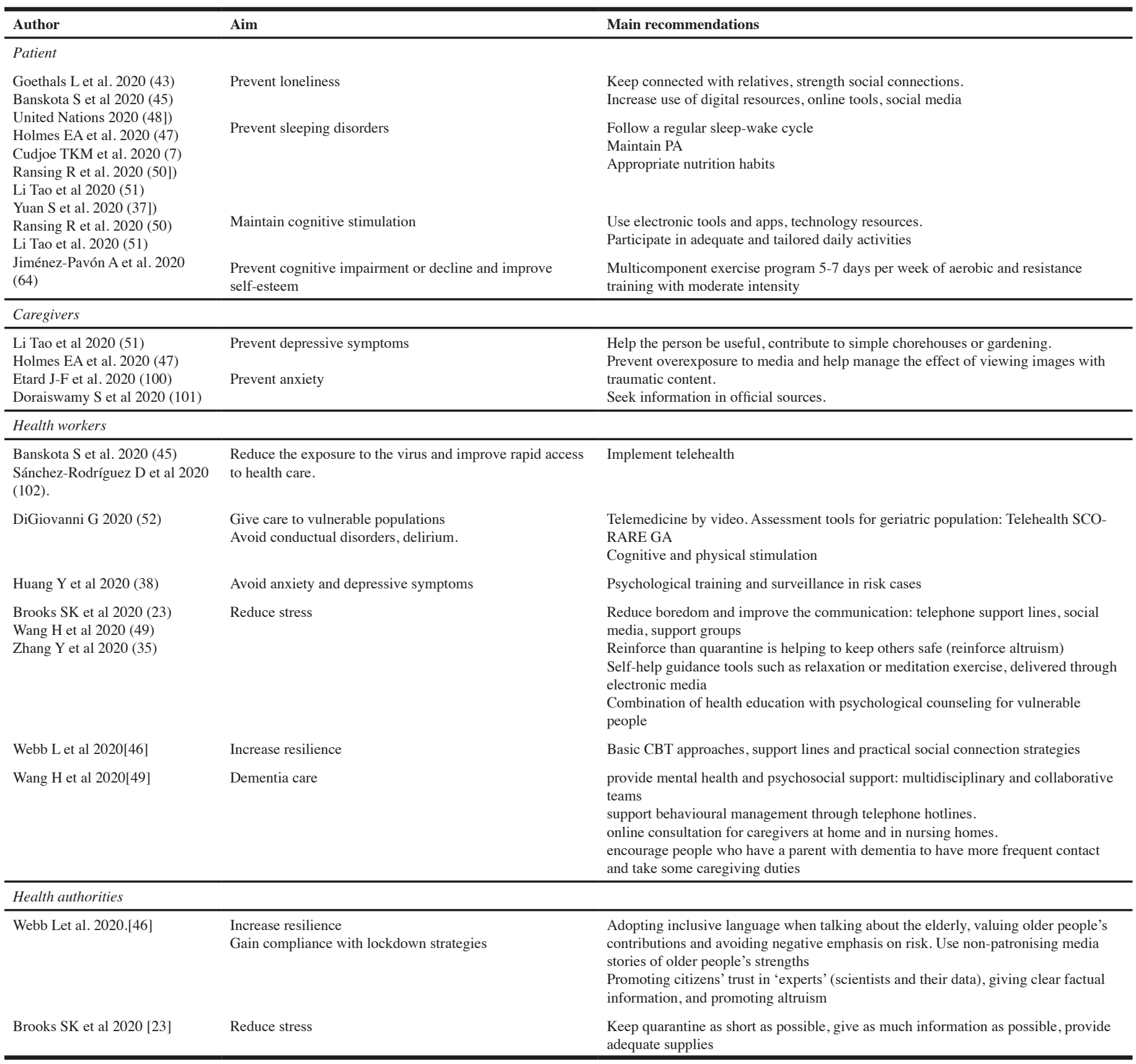

Reinforcing that being quarantined is helping to keep others safe $(23,35,46,49)$, adopting inclusive language when talking about the elderly, valuing older people's contributions and avoiding negative emphasis on risk (46) could increase also elderly's resilience.

During this COVID-19 crisis, healthcare system have had to change completely implementing virtual consultations and telemedicine (video-tools, telephone hotlines or online consultations (49), guaranteeing rapid access to health care (52, 56). Additionally, the SCORARE GA, an assessment tool, has been proposed for doing a telematic geriatric assessment (52).

In order to minimize isolation related stress, quarantine should be as short as possible. Giving good quality information, using channels that older people use like traditional media is also important for reducing stress (23). 
IMPACT OF SOCIAL ISOLATION DUE TO COVID-19 ON HEALTH IN OLDER PEOPLE

\section{Table 2B}

Recommendations of the literature for maintaining physical health in older people during the COVID-19 quarantine

\begin{tabular}{|c|c|c|}
\hline Author & Aim & Main recommendations \\
\hline \multicolumn{3}{|l|}{ Patient } \\
\hline ACSM 2020 (58) & $\begin{array}{l}\text { Maintaining or increasing physical activity } \\
\text { level }\end{array}$ & $\begin{array}{l}\text { - 150-300 minutes per week of moderate-intensity aerobic PA and } 2 \text { sessions per week of muscle } \\
\text { strength training } \\
\text { - Exercise at home using the technology, music, app from your smart phone } \\
\text { - Examples of home-based exercises: Aerobic indoor activities such as dancing to your favourite } \\
\text { music, following an exercise video, and using home cardio machines if you have them. Outdoor } \\
\text { activities (if allowed by your government) such as walking around you neighbourhood staying } 6 \text { feet } \\
\text { away from others. Strength training such as squats or sit-to-stand. More activities are reported in the } \\
\text { document (58) }\end{array}$ \\
\hline
\end{tabular}

AHA 2020 (59)

- Exercise circuit at home. Alternative cardio and strength exercises in short bursts of 30 seconds for up to 3 minutes, two or three series

- Examples of home-based exercises: Cardio exercises such as jumping jacks, squat jumps and step-ups. Strengthening and stability exercise such as hip lift, sit-ups, and lunges. More activities are reported online (59)

APTA $2020(60)$

- Several resources that have been developed to encourage PA while people are social distancing and staying in their homes, such as online videos from the website ChoosePT (66)

WHO $2020(62)$

- 150 minutes of moderate-intensity or 75 minutes of vigorous-intensity PA per week, or a combination of both

- Exercise at home using technology and online exercise class of videos on YouTube

- Examples of home-based exercises: Knee to elbow, plank, squats, legs up the wall. More activities are reported online $(62)$

Roshel et al 2020 (103)

- PA recommendations for older adults ( $\geq 65$ years of age) adapted from the WHO's recommendations $(62)$

Rodríguez et al 2020 (104)

ACSM $2020(58)$

Pinto et al $2020(65)$

Mohamed et al 2020 (105)

Improve immune and respiratory functions

- Exercise recommendations for older people from International organizations $(58,59,62)$

- A video from ACSM partner National Center on Health, Physical Activity and Disability (NCHPAD) (67)

- Strategies such as 'move more and sit less during the day' can be promoted: breaking up prolonged sedentary time ( 2 minutes of walking for every 30 minutes of sitting)

Aerobic exercise such as routine of 10 to 30 minutes of mild to moderate intensity

\section{Caregivers}

Pinto et al $2020(65)$

Consideration for special cases

- For patients with physical limitations and unstable chronic diseases, home- based exercise programmes designed for the general population might not be ideal and safety. Therefore, they need supervision during the exercise

Professionals Health

Jiménez-Pavón et al 2020 (64) Design a multicomponent program at home

The principal elements to consider are:

- Modality: multicomponent exercise (aerobic, resistance, balance, coordination and mobility training)

- Frequency: 5-7 days/week with adaptation in volume and intensity

- Volume: 150-300 min/week of aerobic exercise, 2 resistance training sessions/week and 2 balance and coordination exercise sessions/week

- Intensity: moderate

- Examples of home-based exercises: Resistance training through bodyweight exercises such as squats holding a chair, sitting and getting up from the chair or going up and down a step, transporting items with light and moderate weights (vegetables, rice, water, etc), aerobic exercises like walking inside the house, dancing or balance exercise such as walking on a line on the floor, walking on the toes or heels, walking heel-to-toe, and stepping over obstacles

WCPT and INPTRA $2020 \quad$ Implement Telehealth (63)

- Digital PA practice and telehealth to facilitate effective delivery of physical therapy services by improving access to care and information and managing health care resources. WCPT and INPTRA recommended the online platform through the internet system when its connectivity is adequate

ACSM: American College of Sports Medicine; AHA: American Heart Association; APTA: American Physical Therapy Association; INPTA: International Network of Physiotherapy Regulatory Authorities; IPTOP: International Association of Physical Therapists working with Older People; PA: Physical activity. WCPT: World Confederation for Physical Therapy; WHO: World Health Organization. 
Figure 2

Activities to improve the mental and physical health at home

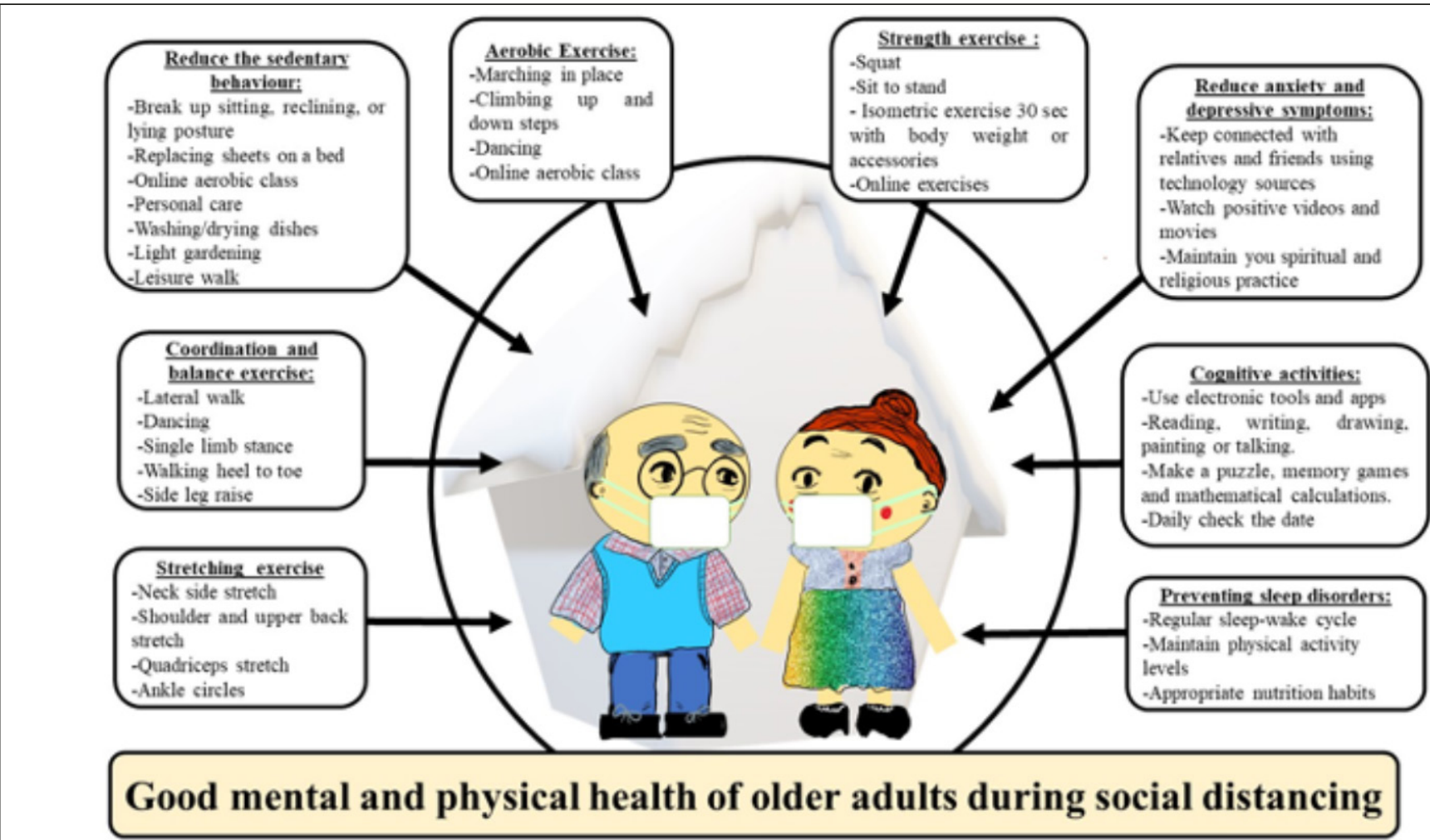

\section{Physical health}

The social distancing has reduced the levels of physical activity, which could have a negative impact on physical health $(43,44)$. In this review, we include recommendations about increasing physical activity levels from the following eight global organizations: American College of Sports Medicine (ACSM) (57), American Heart Association (AHA) (58), American Physical Therapy Association (APTA) (59), International Association of Physical Therapists working with Older People (IPTOP) (60), World Health Organization (WHO) (61), World Confederation for Physical Therapy (WCPT) and International Network of Physiotherapy Regulatory Authorities (INPTRA) (62). They recommended 150-300 minutes per week of moderate-intensity aerobic physical activity and two sessions per week of muscle strength training $(57,61)$. Additionally, exercise circuit at home with cardio and strength exercises in short bursts of 30 seconds for up to three minutes. Finally, coordination, mobility and cognitive exercises are also necessary (63) (Table 2B).

The role of caregivers during the quarantine is to supervise the exercise in those patients with unstable chronic diseases (64). For health professionals, the principal elements to consider when designing an exercise program for older people confined at home are exercise modality, frequency, volume, and intensity (63). It is recommended the telehealth using online videos, apps online platform for phones and tablets through the internet system $(60,62,65)$. IPTOP has recommended a list of apps[60] such as "Otago exercise programme", "Clock yourself" and "iPrescribe Exercise". APTA, ACSM and AHA recommended different online videos and websites $(58,65,66)$ (Table 2B).

\section{Discussion}

\section{Mental health}

This review suggests a general negative effect on mental health in general population during social isolation for COVID19. This implies higher levels of anxiety and depression as well as poorer sleep quality.

The prevalence of anxiety and depression during COVID-19 outbreak, varies across the studies, having a wide range from $8.3 \%$ (36) to $49.7 \%$ (42) for anxiety or $14.6 \%$ (36) to $47.2 \%$ (42) for depression, in consonance with previous studies of other epidemics. For instance, 39\% of prevalence of anxiety was observed in France due to avian influenza (67); $48 \%$ of the general population in Sierra Leone experimented symptoms of anxiety or depression 1 year after Ebola outbreak (68); in Hong Kong due to the SARS epidemic, $73 \%$ and $57 \%$ of individuals presented low mood and irritability (respectively) (33), as well as depression in $31.2 \%$ of 129 quarantined persons for SARS epidemic in 2003 (69). The lower rates of anxiety and depression observed in some studies of our review during 
IMPACT OF SOCIAL ISOLATION DUE TO COVID-19 ON HEALTH IN OLDER PEOPLE

coronavirus pandemic could be explained for several reasons. The first one is that, based on previous epidemics, strong and quickly measures to keep mental health could have been taken by the governments, avoiding a bigger psychological impact. As time goes by, there was more information about SARSCov-2, which could also lead to a better management of the situation. However, data were collected in a very earlier stage of the pandemic, hence, these results should be taken with caution.

Some of the risk factors associated to a higher risk of psychological distress have been also described in previous literature. After Ebola outbreak, people who knew someone quarantined due to Ebola or with any Ebola experience were at higher risk of anxiety, depression and post-traumatic stress disorder (68). Additionally, being older than 60 or worried about the recurrence of SARS have been also found as risk factors in previous studies (70). However, we cannot conclude the same in this review, where a more intense effect on older people has not been reported. Another parameter that should be taken into account is the duration of isolation, since it is related to the severity of psychological symptoms. A non-significant impact on patients' well-being has been demonstrated during short-term isolation (71).

Health providers need to be aware that older adults are at higher risk of having mental health concerns during isolation, and they may have less resources to mitigate them. They should encourage old adults and their families to contact each other daily, as much as they can, to reduce isolation in this population. Additionally, maintaining a positive life-style behavior such as regular sleep and meal times, keep a healthy diet, cognitive stimulation and perform physical activity need to be recommended. Also, relaxation techniques which may include diaphragmatic respirations or muscular relaxation, practicing a regular routine, alternating with different activities during the day could be useful. It is important for people to be informed by reliable sources and spending a limited time for searching information, maximum once or twice per day. Information given to the elderly should be simple, frequent, and displayed in appropriate media.

\section{Physical health}

This review has reported that social distancing because of the COVID-19 pandemic could lead to negative consequences for the physical health of older adults. This is caused by the decrease of physical activity levels due to the total or partial restriction of social participation in community groups and family activities during the pandemic $(42,43,44)$.

Social participation has several positive effects on physical health in elderly people (72). Studies have reported that older adults who were enrolled into social activities presented better dynamic balance and muscle strength, healthy lung function and lower disabilities and chronic inflammation compared to those without social participation $(14,72)$. For this reason, attending social activities is an important component for successful aging
$(14,72)$.

The relationship between social interaction and physical health may operate through different pathways $(14,72)$. A possible explanation for these findings is that participating in meetings or social activities stimulates the musculoskeletal, cardiovascular, respiratory and nervous systems through physical activity and social interaction (73). Physical activity generates benefits for the physical health of older adults, stimulating muscle contraction, energy expenditure, decreasing systemic inflammation and oxidative stress, reducing prevalence of chronic diseases, and geriatric syndromes such as sarcopenia, osteosarcopenia and frailty (74).

As expected decreasing or total restriction of social interaction could generate negative consequences for the health of elderly people, especially in those with chronic diseases, disabilities and geriatric syndromes $(14,63)$. Evidence has demonstrated a relationship between social isolation and loneliness with disability, chronic diseases, risk of mortality and physical inactivity in elderly population $(9,19,75-79)$. However, the effect of increased sedentary behavior and decreased physical activity on elderly people during the COVID-19 pandemic is unclear.

Isolated older people have less physical activity and more sedentary behavior than those non-isolated[80]. Physical activity is described as any body movement using skeletal muscle that results in energy expenditure $>1.5$ metabolic equivalent of task (MET), while sedentary behavior is defined as any waking behavior characterized by an energy expenditure 1.5 or less MET while in a sitting, reclining or lying posture $(81,82)$. Increased sedentary behavior has been associated with the prevalence of different comorbidities in elderly people (83). Since a direct association has been reported between sedentary time and time spent at home in elderly people (84), recommendations have to be made to prevent health consequences in people with social isolation associated to the pandemic COVID-19.

The global expert organizations included in this review have highlighted the importance of increasing or maintaining the physical activity levels during the pandemic (57-62). Although those organization recommended different types of activities or exercises, they are in agreement of using online videos, apps online platform for phones and tablets through the internet system $(60,62,65)$. ACSM and WHO recommended 150-300 minutes per week of aerobic physical activity and 2 sessions per week of muscle strength training $(57,61)$. However, recommendations for people with social isolation could consider studies that have reported benefits of replacing sedentary time with physical activity. For example, replacing sedentary behavior with 30 minutes of light physical activity and 20 minutes of moderate to vigorous physical activity could have beneficial effects on all cause mortality (85). In addition, replacing 30 minutes per day of sedentary time with moderate to vigorous physical activity has been associated with a decreased frailty in older people (86). This information 


\section{THE JOURNAL OF NUTRITION, HEALTH \& AGING}

could be used to recommend physical activity as appealing and feasible (87). Additionally, balance, coordination, mobility and cognitive exercises to stimulate neurological system are recommended for older people to reduce the risk of falls and cognitive declining (63). In those older adults with geriatrics syndromes or unstable chronic diseases, it is recommended the supervision of caregivers to avoid falls, exacerbations and injuries during the exercise (64). In addition, the health professionals should design the exercise program for older people confined at home with a specific exercise modality, frequency, volume, and intensity (63), using online videos, apps online platform for phones and tablets through the internet system $(60,62,65)$.

Finally, the quarantine implied a radical change in the lifestyle of elderly people, reducing the social interaction, participation in exercise group, religious or spiritual group which have negatively affected the mental and physical health in this population (88). Therefore, to maintain an active lifestyle at home is important for the health of older adults, especially those with chronic diseases and geriatrics syndromes. To summarize all the recommendations and articles included in this review, we have proposed different activities to improve the mental and physical health at home in Figure 2.

\section{Limitations}

To the best of our knowledge, this is the first review that includes assessing the physical and mental effects of social isolation by COVID-19 among older people. However, this study has some limitations, which deserve to be mentioned. Studies included in this review were cross-sectional design and not specific in elderly population. As all of them are descriptive studies, no control group was used. Additionally, there is also a lack of evidence regarding the most appropriate psychological and physical recommendations and most of the interventions suggested are based on expert opinions and not on high evidence studies. Future investigations should consider a longitudinal or cross-sectional design in older individuals, with larger sample size and different outcomes related to mental and physical health.

\section{Conclusion}

In conclusion, our study suggests that the mental and physical health in older people are negatively affected during the social distancing for COVID-19. The main mental and physical outcomes reported were anxiety, depression, poor sleep quality and physical inactivity during the isolation period. Experts organizations and WHO have given different recommendations to keep older people mentally and physically healthy. Therefore, an integrated and multidisciplinary assessment between geriatricians, psychiatrists and physiotherapists could be needed.

Declaration of Conflict of Interest: None.
Declaration of Sources of Funding: co-financed by the European Regional Development Funds (RD120001/0043) and the Centro de Investigación Biomédica en Red en Fragilidad y Envejecimiento Saludable-CIBERFES (CB16/10/00464).

Author's contribution: Study concept and design: all authors. Data collection: WSL, IRS, RT. Draft of the manuscript: WSL, IRS, PPR, FG, RT. Full access to all of the data in the study and responsibility for the integrity of the data: WSL, IRS. Study supervision: LRM. All authors reviewed the manuscript for important intellectual content and approved the final version.

\section{References}

1. Jones DS. History in a Crisis - Lessons for Covid-19. N Engl J Med. 2020:1-2. doi:10.1056/NEJMp2004361

2. World Health Organization. COVID-19 Strategy Up Date. World Heal Organ. 2020;(April). https://www.who.int/publications-detail/covid-19-strategy-update---14april-2020

3. WHO. Statements, press and ministerial briefings. 2020. http://www.euro.who.int/en health-topics/health-emergencies/coronavirus-covid-19/statements.

4. Zazhi ZLX. The epidemiological characteristics of an outbreak of 2019 novel coronavirus diseases (COVID-19) in China. Epidemiol Work Gr NCIP Epidemic Response, Chinese Cent Dis Control Prev. 2020;41(2):145-151. doi:10.3760/ cma.j.issn.0254-6450.2020.02.003

5. Bialek S, Boundy E, Bowen V, et al. Severe Outcomes Among Patients with Coronavirus Disease 2019 (COVID-19) - United States, February 12-March 16, 2020. MMWR Morb Mortal Wkly Rep. 2020;69(12):343-346. doi:10.15585/mmwr. mm6912e2

6. Rudolph CW, Zacher H. "The COVID-19 Generation": A Cautionary Note. Work Aging Retire. 2020;XX(Xx):1-7. doi:10.1093/workar/waaa009

7. Cudjoe TK, Kotwal AA. "Social distancing" amidst a crisis in social isolation and loneliness. J Am Geriatr Soc. 2006;50(6):776-780. doi:10.1111/1462-2920.12735

8. Who. The International Classification of Functioning, Disability and Health. World Heal Organ. 2001;18:237. doi:10.1097/01.pep.0000245823.21888.71

9. Loyola WS, Camillo CA, Torres CV, Probst VS. Effects of an exercise model based on functional circuits in an older population with different levels of social participation. Geriatr Gerontol Int. 2017. doi:10.1111/ggi.13167

10. Sirven N, Debrand T. Social participation and healthy ageing: An international comparison using SHARE data. Soc Sci Med. 2008;67(12):2017-2026. doi:10.1016/j. socscimed.2008.09.056

11. Pollack CE, von dem Knesebeck O. Social capital and health among the aged: comparisons between the United States and Germany. Health Place. 2004;10(4):383391. doi:10.1016/j.healthplace.2004.08.008

12. Yazawa A, Inoue Y, Fujiwara T, et al. Association between social participation and hypertension among older people in Japan: The JAGES Study. Hypertens Res. 2016;39(11):818-824. doi:10.1038/hr.2016.78

13. Douglas H, Georgiou A, Westbrook J. Social participation as an indicator of successful aging: An overview of concepts and their associations with health. Aust Heal Rev. 2017:41(4):455-462. doi:10.1071/AH16038

14. Sepúlveda-Loyola W, Ganz F, Maciel RPT, et al. Social participation is associated with better functionality, health status and educational level in elderly women. Brazilian J Dev. 2020;5(6):5983-5992. doi:10.34117/bjdv6n4-035

15. Smith GL, Banting L, Eime R, Sullivan GO, Uffelen JGZ Van. The association between social support and physical activity in older adults : a systematic review. 2017:1-21. doi:10.1186/s12966-017-0509-8

16. Yazawa A, Inoue Y, Fujiwara T, et al. Association between social participation and hypertension among older people in Japan: the JAGES Study. Hypertens Res 2016;39(11):818-824. doi:10.1038/hr.2016.78

17. Chiao C, Weng LJ, Botticello AL. Social participation reduces depressive symptoms among older adults: An 18-year longitudinal analysis in Taiwan. BMC Public Health. 2011;11. doi:10.1186/1471-2458-11-292

18. Wallace LMK, Theou O, Pena F, Rockwood K, Andrew MK. Social vulnerability as a predictor of mortality and disability: cross-country differences in the survey of health, aging, and retirement in Europe (SHARE). Aging Clin Exp Res. 2015;27(3):365-372. doi:10.1007/s40520-014-0271-6

19. Holt-Lunstad J, Smith TB, Layton JB. Social relationships and mortality risk: A metaanalytic review. PLoS Med. 2010;7(7). doi:10.1371/journal.pmed.1000316

20. Choi NG, DiNitto DM, Marti CN. Social participation and self-rated health among older male veterans and non-veterans. Geriatr Gerontol Int. 2016;16(8):920-927. doi:10.1111/ggi.12577

21. Tomioka K, Kurumatani N, Hosoi H. Social Participation and the Prevention of Decline in Effectance among Community-Dwelling Elderly: A Population-Based Cohort Study. PLoS One. 2015;10(9):e0139065. doi:10.1371/journal.pone.0139065

22. Croezen S, Avendano M, Burdorf A, Lenthe FJ Van. Social Participation and 


\section{IMPACT OF SOCIAL ISOLATION DUE TO COVID-19 ON HEALTH IN OLDER PEOPLE}

Depression in Old Age : A Fixed-Effects Analysis in 10 European Countries. 2015. doi:10.1093/aje/kwv015

23. Brooks SK, Webster RK, Smith LE, et al. The psychological impact of quarantine and how to reduce it: rapid review of the evidence. Lancet. 2020;395(10227):912-920. doi:10.1016/S0140-6736(20)30460-8

24. Morley JE, Vellas B. COVID-19 and Older Adults. J Nutr Health Aging. 2020;24(4):364-365. doi:10.1007/s12603-020-1349-9

25. Armitage R, Nellums LB. COVID-19 and the consequences of isolating the elderly. Lancet Public Heal. 2020;2667(20):30061. doi:10.1016/S2468-2667(20)30061-X

26. Beard JR, Officer A, De Carvalho IA, et al. The World report on ageing and health: A policy framework for healthy ageing. Lancet. 2016;387(10033):2145-2154. doi:10.1016/S0140-6736(15)00516-4

27. Charles A, Buckinx F, Locquet M, et al. Prediction of Adverse Outcomes in Nursing Home Residents According to Intrinsic Capacity Proposed by the World Health Organization. Journals Gerontol Ser A. 2019. doi:10.1093/gerona/glz218

28. Thiyagarajan JA, De Carvalho IA, Peña-Rosas JP, et al. Redesigning care for older people to preserve physical and mental capacity: WHO guidelines on communitylevel interventions in integrated care. PLoS Med. 2019;16(10). doi:10.1371/journal. pmed.1002948

29. Ozemek C, Lavie CJ, Rognmo Ø. Global physical activity levels - Need for intervention. Prog Cardiovasc Dis. 2019;62(2):102-107. doi:10.1016/j. pcad.2019.02.004

30. Courtin E, Knapp M. Social isolation, loneliness and health in old age: a scoping review. Heal Soc Care Community. 2017;25(3):799-812. doi:10.1111/hsc.12311

31. Yoon MK, Kim SY, Ko HS, Lee MS. System effectiveness of detection, brief intervention and refer to treatment for the people with post-traumatic emotional distress by MERS: A case report of community-based proactive intervention in South Korea. Int J Ment Health Syst. 2016;10(1). doi:10.1186/s13033-016-0083-5

32. DiGiovanni C, Conley J, Chiu D, Zaborski J. Factors influencing compliance with quarantine in Toronto during the 2003 SARS outbreak. Biosecur Bioterror. 2004;2(4):265-272. doi:10.1089/bsp.2004.2.265

33. Lee S, Chan LYY, Chau AMY, Kwok KPS, Kleinman A. The experience of SARS related stigma at Amoy Gardens. Soc Sci Med. 2005;61(9):2038-2046. doi:10.1016/j. socscimed.2005.04.010

34. Yip PSF, Cheung YT, Chau PH, Law YW. The impact of epidemic outbreak: The case of severe acute respiratory syndrome (SARS) and suicide among older adults in Hong Kong. Crisis. 2010;31(2):86-92. doi:10.1027/0227-5910/a000015

35. Zhang Y, Ma ZF. Impact of the COVID-19 pandemic on mental health and quality of life among local residents in Liaoning Province, China: A cross-sectional study. Int J Environ Res Public Health. 2020;17(7). doi:10.3390/ijerph17072381

36. Lei L, Huang X, Zhang S, Yang J, Yang L, Xu M. Comparison of Prevalence and Associated Factors of Anxiety and Depression Among People Affected by versus People Unaffected by Quarantine During the COVID-19 Epidemic in Southwestern China. Med Sci Monit. 2020;26:1-12. doi:10.12659/msm.924609

37. Yuan S, Liao Z, Huang H, et al. Comparison of the Indicators of Psychological Stress in the Population of Hubei Province and Non-Endemic Provinces in China During Two Weeks During the Coronavirus Disease 2019 (COVID-19) Outbreak in February 2020. Med Sci Monit. 2020;26:e923767. doi:10.12659/MSM.923767

38. Huang Y, Zhao N. Generalized anxiety disorder, depressive symptoms and sleep quality during COVID-19 outbreak in China: a web-based cross-sectional survey. Psychiatry Res. 2020;288. doi:10.1016/j.psychres.2020.112954

39. Mazza C, Ricci E, Biondi S, et al. A Nationwide Survey of Psychological Distress among Italian People during the COVID-19 Pandemic: Immediate Psychologica Responses and Associated Factors. Int J Environ Res Public Health. 2020;17(9). doi:10.3390/ijerph17093165

40. Ozamiz-etxebarria N, Dosil-santamaria M, Picaza-gorrochategui M, Idoiagamondragon N. Stress, anxiety, and depression levels in the initial stage of the COVID-19 outbreak in a population sample in the northern Spain. Cad Saude Publica. 2020;36(4):1-9. doi:10.1590/0102-311X00054020

41. Carlos Miguel Rios-González JMP. Symptoms of Anxiety and depression during the outbreak of COVID-19 in Paraguay. Symptoms Anxiety Depress Dur outbreak COVID-19 Paraguay. 2020

42. Losada-Baltar A, Jimenez-Gonzalo L, Gallego-Alberto L, Pedrosos-Chaparro M del S Fernades-Pires J, Marquez-Gonzáles M. "We're staying at home". Association of selfperceptions of aging, personal and family resources and loneliness with psychological distress during the lock-down period of COVID- 19. J Gerontol B Psychol Sci Soc Sci. 2020:1-10.

43. Goethals L, Barth N, Guyot J, Hupin D, Celarier T, Bongue B. Impact of home quarantine on physical activity among older adults living at home during the COVID19 pandemic: Qualitative interview study. J Med Internet Res. 2020;22(5):1-5. doi: $10.2196 / 19007$

44. Castañeda-babarro A. Impact of COVID-19 confinement on the time and intensity of physical activity in the Spanish population. Res Sq. 2020:1-14. doi:10.21203/ rs.3.rs-26074/v1

45. Banskota S, Healy M, Goldberg E. 15 Smartphone Apps for Older Adults to Use While in Isolation During the COVID-19 Pandemic. West J Emerg Med. 2020;21(3) doi:10.5811/westjem.2020.4.47372

46. Webb L. Covid-19 lockdown: a perfect storm for older people's mental health. J Psychiatr Ment Health Nurs. 2020. doi:10.1111/jpm.12644

47. Holmes EA, O'Connor RC, Perry VH, et al. Multidisciplinary research priorities for the COVID-19 pandemic: a call for action for mental health science. The Lancet Psychiatry. 2020;0366(20):1-14. doi:10.1016/S2215-0366(20)30168-1

48. Brief P. Policy Brief : The Impact of COVID-19 on Older Persons.; 2020

49. Huali Wang, Tao Li, Paola Barbarino, Serge Gauthier, Henry Brodaty, José Luis Molinuevo, Hengge Xie, Yongan Sun, Enyan Yu, Yanqing Tang, Wendy Weidner *Xin Yu. Dementia care during covid. 2020;(January). doi:10.1148/ radiol.2020200642.Inui

50. Ransing R, Adiukwu F, Pereira-Sanchez V, et al. Mental Health Interventions during the COVID-19 Pandemic A Conceptual Framework by Early Career Psychiatrists. Asian J Psychiatr. 2020;51(April):102085. doi:10.1016/j.ajp.2020.102085

51. Chinese Society of Geriatric Psychiatry, Alzheimer's disease chinese, Psychogeriatric Interest Group of Chinese Society of Psychiatry et al. Expert recommendations on mental health and psychosocial support for persons with cognitive disorders and their caregivers during the COVID-19 outbreak. Chinese J Psychiatry. 2020;53(2):89-94

52. DiGiovanni G, Mousaw K, Lloyd T, et al. Development of a telehealth geriatric assessment model in response to the COVID-19 pandemic. J Geriatr Oncol. 2020. doi:10.1016/j.jgo.2020.04.007

53. Doraiswamy S, Cheema S, Mamtani R. Older people and epidemics: a call for empathy. Age Ageing. 2020;(March):2020. doi:10.1093/ageing/afaa060

54. Holmes EA, O'Connor RC, Perry VH, et al. Multidisciplinary research priorities for the COVID-19 pandemic: a call for action for mental health science. The Lancet Psychiatry. 2020;0366(20):1-14. doi:10.1016/S2215-0366(20)30168-1

55. Etard J-F, Vanhems P, Atlani-Duault L, Ecochard R. Potential lethal outbreak of coronavirus disease (COVID-19) among the elderly in retirement homes and long-term facilities, France, March 2020. Eurosurveillance. 2020;25(15):8-10. doi:10.2807/1560 7917.es.2020.25.15.2000448

56. Mahmoodpoor A, Akbarzadeh MA, Sanaie S, Hosseini MS. Role of Telehealth in Outbreaks - Where the Classic Healthcare Systems Fail. Infect Control Hosp Epidemiol. 2020. doi:10.1017/ice.2020.120

57. ACSM. Staying Active During the Coronavirus Pandemic.; 2020. doi:10.1089/ dna.2020.29015.cs

58. AHA. Create a Circuit Home Workout Infographic. https://www.heart.org/en/healthyliving/fitness/getting-active/create-a-circuit-home-workout. Published 2020.

59. APTA. Patient Management Adult. http://www.apta.org/PatientCare/COVID-19/ PatientManagementAdult/. Published 2020.

60. IPTOP. Resources for exercise and physical activity. https://drive.google.com/ file/d/1BFyj8_H3J2mtJndlgkszzsunDvoc2zdp/view. Published 2020.

61. WHO. Stay physically active during self-quarantine. http://www.euro.who.int/en/ health-topics/health-emergencies/coronavirus-covid-19/novel-coronavirus-2019-ncovtechnical-guidance-OLD/stay-physically-active-during-self-quarantine. Published 2020 .

62. WCPT. REPORT OF THE WCPT / INPTRA DIGITAL PHYSICAL THERAPY. 2020;(March)

63. Jiménez-Pavón D, Carbonerll-Baeza A, Lavie CJ. Physical exercise as therapy to fight against the mental and physical consequences of COVID-19 quarantine: Special focus in older people. Prog Cardiovasc Dis. 2020;(January).

64. Pinto AJ, Dunstan DW, Owen N, Bonfá E, Gualano B. Combating physical inactivity during the COVID-19 pandemic. Nat Rev Rheumatol. 2020:19-20. doi:10.1038/ s41584-020-0427-z

65. ChoosePT. Home Exercises from a Physical Therapist. https://www.choosept.com/ patientresources/videolibrary/detail/home-exercises-from-physical-therapist-floor-mat

66. National Center on Health PA and D (NCHPAD). Exercising at Home: Strength and Cardio. https://www.youtube.com/ watch?list=PLwMObYmlSHaPIArTOC4JBZfeuU7LN7KVJ\&v=eLClKvN9Qag Published 2019.

67. Saadatian-Elahi M, Facy F, Del Signore C, Vanhems P. Perception of epidemic's related anxiety in the General French Population: A cross-sectional study in the RhneAlpes region. BMC Public Health. 2010;10. doi:10.1186/1471-2458-10-191

68. Jalloh MF, Li W, Bunnell RE, et al. Impact of Ebola experiences and risk perceptions on mental health in Sierra Leone, July 2015. BMJ Glob Heal. 2018;3(2):1-11. doi:10.1136/bmjgh-2017-000471

69. Hawryluck L, Gold WL, Robinson S, Pogorski S, Galea S, Styra R. SARS control and psychological effects of quarantine, Toronto, Canada. Emerg Infect Dis. 2004;10(7):1206-1212. doi:10.3201/eid1007.030703 


\section{THE JOURNAL OF NUTRITION, HEALTH \& AGING}

70. Eugene Yu-Chang Peng,1,2 Ming-Been Lee,3 Shang-Ta Tsai,4 Chih-Chien Yang,5 Donald Edward Morisky,6 Liang-Ting Tsai,5 Ya-Ling Weng 2 Shu-Yu Lyu2*. Population-based Post-crisis Psychological Distress: An Example From the SARS Outbreak in Taiwan. J Formos Med Assoc. 2010;109(7):524-532.

71. Day HR, Perencevich EN, Harris AD, et al. Depression, Anxiety, and Moods of Hospitalized Patients under Contact Precautions. Infect Control Hosp Epidemiol 2013;34(3):251-258. doi:10.1086/669526

72. Tomioka K, Kurumatani N, Hosoi H. Association Between Social Participation and 3-Year Change in Instrumental Activities of Daily Living in Community-Dwelling Elderly Adults. J Am Geriatr Soc. 2017;65(1):107-113. doi:10.1111/jgs.14447

73. Fernandez-Alonso L, Muñoz-García D, La Touche R. The level of physical activity affects the health of older adults despite being active. J Exerc Rehabil. 2016;12(3):194201. doi: $10.12965 /$ jer. 1632566.283

74. Arazi H, Eghbali E. Osteosarcopenia and Physical Activity. Ann Sport Med Res. 2018;5(1130):3-6

75. Saito M, Kondo K, Ojima T, Hirai H, JAGES group. Criteria for social isolation based on associations with health indicators among older people. A 10-year follow-up of the Aichi Gerontological Evaluation Study. Nihon Koshu Eisei Zasshi. 2015;62(3):95105. doi:10.11236/jph.62.3_95

76. Schrempft S, Jackowska M, Hamer M, Steptoe A. Associations between social isolation, loneliness, and objective physical activity in older men and women. BMC Public Heal. 2019;19(1):74.

77. Heffner K, Waring M, Roberts M, Eaton C, Gramling R. Social isolation, C-reactive protein, and coronary heart disease mortality among community-dwelling adults. Soc Sci Med. 2011;72(9):1482-8.

78. Patterson A, Veenstra G. Loneliness and risk of mortality: a longitudinal investigation in Alameda County, California. Soc Sci Med. 2010;71(1):181-186.

79. Valtorta N, Kanaan M, Gilbody S, Ronzi S, Hanratty B. Loneliness and social isolation as risk factors for coronary heart disease and stroke: systematic review and meta-analysis of longitudinal observational studies. Heart. 2016;102(13):1009-16.

80. Reed S, Crespo C, Harvey W, Andersen R. Social isolation and physical inactivity in older US adults: Results from the Third National Health and Nutrition Examination Survey. Eur J Sport Sci. 2011;11(5):347-353.

81. Tremblay MS, Aubert S, Barnes JD, et al. Sedentary Behavior Research Network (SBRN) - Terminology Consensus Project process and outcome. Int J Behav Nut Phys Act. 2017;14(1). doi:10.1186/s12966-017-0525-8

82. Caspersen CJ, Powell KE, Christenson GM. Physical activity, exercise, and physical fitness: definitions and distinctions for health-related research. Public Health Rep. 1985;100(2):126-131. doi: 10.2307/20056429

83. de Rezende L, Rey-López J, Matsudo V, do Carmo Luiz O. Sedentary behavior and health outcomes among older adults: a systematic review. BMC Public Heal 2014;9(14):333.

84. Jansen FM, Prins RG, Etman A, et al. Physical activity in non-frail and frail older adults. PLoS One. 2015;10(4). doi:10.1371/journal.pone.0123168

85. Dohrn I-M, Kwak L, Oja P, Sjostrom M, Hagstromer M. Replacing sedentary time with physical activity: a 15-year follow-up of mortality in a national cohort. Clin Epidemiol. 2018;Volume 10:179-186. doi:10.2147/CLEP.S151613

86. Mañas A, Del Pozo-Cruz B, Guadalupe-Grau A, et al. Reallocating AccelerometerAssessed Sedentary Time to Light or Moderate- to Vigorous-Intensity Physical Activity Reduces Frailty Levels in Older Adults: An Isotemporal Substitution Approach in the TSHA Study. Am Med Dir Assoc. 2018;19(2):185.e1-185.e6.

87. Ezeugwu VE MP. The Feasibility and Longitudinal Effects of a Home-Based Sedentary Behavior Change Intervention After Stroke. Arch Phys Med Rehabil 2018;99(12):2540-2547.

88. Vahia I V., Blazer DG, Smith GS, et al. COVID-19, Mental Health and Aging: A Need for New Knowledge to Bridge Science and Service. Am J Geriatr Psychiatry. 2020;(January). doi:10.1016/j.jagp.2020.03.007 